\title{
Research trends in outdoor pig production - A review
}

\author{
Hyun-Suk Park ${ }^{1}$, Byungrok Min², and Sang-Hyon $\mathrm{Oh}^{1, *}$
}

\author{
* Corresponding Author: Sang-Hyon Oh \\ Tel: +1-336-285-4807, Fax: +1-336-334-7288 \\ E-mail: soh@ncat.edu \\ 'Department of Animal Sciences, College of \\ Agriculture and Environmental Sciences, North \\ Carolina A\&T State University, NC 27411, USA \\ 2 Department of Agriculture, Food and Resource \\ Sciences, University of Maryland Eastern Shore, \\ Princess Anne, MD 21853, USA
}

Submitted Apr 29, 2017; Revised Jun 14, 2017; Accepted Jul 11, 2017

\begin{abstract}
Since the industrialization of swine production in the late 1900s, swine farms in the United States, as well as in Europe, have largely become consolidated. Pig farms became larger in size but fewer in number, with $91 \%$ of market pigs being produced by large operations with 5,000 or more pigs on-site in the US, and only $3 \%$ of the total utilized agricultural land representing organic farming. Such change in the market made it difficult for small farmers to stay competitive, forcing them to find alternative ways to reduce the cost of production and increase profit using the outdoor production system. In contrast to the indoor confinement system, outdoor production system uses pasture-based units and/or deep-bedded hoop structures that promote animal welfare and environmental sustainability with a lower capital investment. In accord with the growing concern for animal and environmental welfare and food safety by the consumers, small farmers practicing an outdoor production system are seeing increased opportunities for marketing their products in the pork niche market. Unlike the general belief that the reproductive and growth performance measures of the outdoor sows and piglets are poorer in comparison with the animals reared indoors, studies showed that there was no significant difference in the performance measures, and some traits were even better in outdoor animals. Improved reproductive and production traits can increase the sustainability of outdoor farming. Present study reviewed the recent studies comparing the performance measures, meat quality and health of indoor and outdoor animals, as well as the efforts to improve the outdoor production system through changes in management such as hut types and breed of animals.
\end{abstract}

Keywords: Outdoor; Pig; Production; Research; Review

\section{INTRODUCTION}

Pork production in the United States is predominated by the intensive, indoor confinement system. In 2012, 91\% of market pigs were produced by large operations with 5,000 or more pigs on-site [1]. However, the large operation sites only consisted of $13 \%$ of the total pig farms in the US. This is the result of the rapid industrialization of livestock production that occurred in the late 1900s. With a strong emphasis on efficiency, the pig farms in the US became larger in size, but fewer in number [2]. Similar trend is observed in Europe [3]. Though consumer awareness of food safety issues and environmental concerns are growing, and organic farming grew approximately $25 \%$ to $30 \%$ in recent years as a result, it only represents about $3 \%$ of the total EU utilized agricultural area $[4,5]$.

Since its development, the intensive, indoor production system received criticism for its potential harm on the environment that poses problems to sustainability in both the US [6] and in Europe [7]. Outdoor production systems, on the other hand, has the potential to solve these environmental issues, as well as food safety concerns, while providing animal welfare and new opportunities for small, limited-resource farmers [8]. The relatively small investment cost, compared to the indoor confinement system, and the potential for added value make outdoor production a good alternative for the small farmers [9]. The purpose of the present paper is to review the recent research efforts to improve the sow and piglet performances, and meat quality for outdoor 
production systems.

\section{REPRODUCTIVE PERFORMANCE}

Outdoor production is believed to have higher mortality rate than indoor production, with crushing by sow being the number one reason [7]. However, study shows that there really isn't much difference between the two production systems [10], and there is a tendency to overestimate crushing [11]. Johnson et al [10] compared the reproductive performance of lactating sows in indoor and outdoor environments. In the study, the sows were either housed in indoor conventional farrowing crates, measuring $2.1 \times 0.6$ $\mathrm{m}^{2}$ with a $2.1 \times 0.46 \mathrm{~m}^{2}$ creep area, or in English-style arc farrowing huts, measuring $1.12 \mathrm{~m}$ height, $2.79 \mathrm{~m}$ width, and $1.65 \mathrm{~m}$ length, in the outdoors. The researchers collected behavioral data, including active (standing and walking), lying, sitting, drinking, feeding, and nursing interval, and reproductive performance data, including numbers of pigs born, born alive, still-births, mummies, and weaned. Results showed that there was not a significant difference in the reproductive performance of lactating sows in different environments. The outdoor sows did behave more active. While the indoor sows were only active for approximately $9 \%$ of the time, the outdoor sows were active for approximately $28 \%$ of the time $(\mathrm{p}<0.01)$. The researchers observed that the outdoor sows were found at varying distances from their litter at any given time, suggesting that the sows choose to spend time away from their litter to keep nursing stress at a low level. Nonetheless, the amount of contact the sows had with their litter did not differ between the indoor and the outdoor sows.

Even though significant difference was not found between the reproductive performances of the indoor and the outdoor sows, it was found that the outdoor sows had a slightly larger mortality rate, and thus a smaller number of piglets weaned. Number of piglets weaned is directly related to profitability. Different hut designs were considered in order to increase the number of piglets weaned in an outdoor environment. Johnson and McGlone [12] studied the difference in sow performance with different hut designs and the presence of insulation. They used English-style arc farrowing huts with different fender designs, short wooden vs tall metal, and insulated half of the huts with instant foam polyurethane rigid roofing spray foam, applied at a thickness of 1.8 $\mathrm{cm}$ on the sides of the hut and $3.8 \mathrm{~cm}$ on the roof, to compare the reproductive performance of the sows in the different farrowing huts. No performance difference was found between the two hut designs and the presence of insulation ( $p>0.05)$. Though not statistically significant, the hut with the short wooden fender had a slightly higher number of piglets weaned, $8.3 \pm 0.47$ piglets/L. This number is very close to the number of piglets weaned in an indoor environment, $8.4 \pm 0.41$ piglets/L, as reported by Johnson et al [10]. A different study looked at the suitability of different outdoor farrowing hut designs by comparing the temperature and the humidity inside the farrowing huts [13]. The three hut designs used were plastic Nesting Box hut $(G)$, metal English type hut $(\mathrm{S})$, and wood-based Smidley hut $(\mathrm{O})$. Of the three designs, the O type performed better with lower temperature than the $G$ type and lower humidity than both the $G$ and the $S$ types $(p<0.05)$. The authors concluded that the $G$ type hut is recommended for use inside a larger shelter for better protection against the cold in the winter; however, overall performance was the best for the wood-based $\mathrm{O}$ type hut.

In contrast to the results of the studies conducted in the US, comparing the reproductive performances of the sows kept in different environments in Switzerland showed that there were significant differences [14]. When the lifetime cumulative measurements were considered, outdoor sows had significantly lower numbers of total born $(\mathrm{p}<0.01)$, born alive $(\mathrm{p}<0.01)$, and weaned $(p<0.01)$. However, these measures were accumulated over lifetime, and therefore cannot be directly compared with the results of the US studies. A different study conducted in Sweden also studied the effect of rearing environment on the reproductive performance of the sows. Lindgren et al [15] reported that the outdoor reared sows had significantly higher numbers of total born $(\mathrm{p}<0.01)$ and stillborn $(\mathrm{p}<0.01)$ per litter. Furthermore, even though the differences were not significant, the number of pigs born alive per litter was greater for the outdoor reared sows, but the average number of piglets weaned per litter was greater for the indoor reared sows. Swedish researchers also related the lower number of weaned piglets per litter to the opportunity for movement of the sows that result in inadequate nursing and weakening of the piglets, as well as crushing by the sow.

\section{GROWTH PERFORMANCE}

Pigs reared outdoors are generally given more space per pig than those in confinement. Study showed that outdoor reared pigs spent more time walking and playing compared to indoor reared pigs $(\mathrm{p}<0.05)$, and though statistically insignificant, outdoor reared pigs spent more time standing than laying [10]. With longer active period, outdoor reared pigs require more feed to gain the same amount of weight as indoor reared pigs. When given feed ad libitum, outdoor reared barrows had a higher average daily feed intake (ADFI), which resulted in a lower gain:feed (G:F) $(p<0.01)$ [16]. The same study also looked at the effect of birth environment on the growth performance of the barrows. Outdoor born pigs were significantly heavier on 28,56 , and 112 days postweaning ( $\mathrm{p}<0.05)$; however, weight on 140 days post-weaning and the average daily gain (ADG) were not significantly different from those of indoor born pigs ( $p>0.05$ ). The difference between $\mathrm{ADG}$ for outdoor and indoor reared pigs were also insignificant. However, outdoor reared pigs weighed heavier on 140 days postweaning. Different results were reported for gilts reared outdoors [17]. Given feed ad libitum, gilts had higher ADG and a higher feed efficiency (FE). The difference in the performance of the gilts compared to the performance of the pigs may be the result 
of difference in sex and experimental periods. Patton et al [17] assigned the gilts to treatments of either hoop or confinement at 4 months of age, at which their weights ranged from 59 to 71 $\mathrm{kg}$, whereas the pigs in the study by Gentry et al [16] were kept in the study from weaning to 112 days post-weaning. Furthermore, the latter study was conducted in Lubbock, Texas, whereas the study by Patton et al. was conducted in Ames, Iowa $[16,17]$. The climatic conditions in the two states vastly differ, causing the difference in the results.

Growth performance of pigs in an outdoor production system can be largely affected by climatic conditions. Honeyman and Harmon [18] looked at the performance of finishing pigs in hoop structures and confinement during the summer (June to October) and winter (December to April) months in Iowa. The average temperature in the summer is $20^{\circ} \mathrm{C}$ higher than the average temperature in the winter, which falls below freezing point. When pigs were placed in either an outdoor hoop structure or in indoor confinement, no season $\times$ housing type interaction was observed for the start and the end weights ( $\mathrm{p}>0.05)$; however, outdoor reared pigs were heavier at marketing and gained more weight than indoor reared pigs $(\mathrm{p}<0.05)$. Also, the ADFI was significantly higher for the winter $\times$ outdoor hoop group than the rest of the combinations. The same group had the lowest G:F, indicating poor $\mathrm{FE}$. The highest ADG was found among the summer $\times$ outdoor hoop group $(\mathrm{p}<0.05)$. During the winter, the outdoor pigs require higher energy to keep warm than during the summer, resulting in the slower growth rate. Similar results were found in France [19]. An interaction between rearing conditions (confinement vs outdoor) and season (summer vs winter) was found for the feed conversion ratio (FCR). For pigs reared outdoors during the winter, FCR tended to be higher, whereas the opposite was found during the other seasons. Higher FCR indicates higher feed intake necessary to gain the same amount of weight. This may be related to higher energy requirements in outdoor reared pigs for physical exercise and thermoregulation. The interaction between rearing conditions and season was not observed for ADG, and therefore, the results cannot be directly compared to those found in by Honeyman and Harmon [18].

When the two rearing systems were compared in Belgium, France and Sweden, outdoor reared pigs had a higher ADFI and ADG [19-21]. In all three studies, the outdoor reared pigs exhibited heavier hot carcass weight in relation to their heavier live weight at slaughter; however, their lean meat percentage was significantly lower than that of confinement pigs. These results are contradictory to those found in the US. Patton et al [17] reported that outdoor pigs had a significantly lower ADG $(\mathrm{p}<0.01)$ and carcass weight $(\mathrm{p}<0.05)$, but the lean meat percentage of outdoor pigs, calculated as the fat-free lean (FFL) percentage using the National Pork Board \% FFL equation, was significantly higher. Furthermore, American pigs reared outdoors had lower backfat thickness measurements at the 10th and the last ribs [17], compared to the higher fat thickness found in European pigs reared outdoors [20]. The difference in rearing environments should be noted when comparing the results of outdoor reared pigs. In both European studies, the outdoor pigs were reared in an alternative indoor-outdoor system with access to both an indoor sawdust bedding area and an outdoor area made of a concrete floor. In the American study, the outdoor pigs were reared in a deep-bedded hoop barn. The different rearing environment may be the cause of the different results.

Efforts to improve the growth performance of the outdoor finishing pigs are continuously being made. One way of improving the growth performance is through crossbreeding. Finding the best breed for outdoor rearing can help the producers by shortening the days-to-market. Whitley et al [22] compared the growth performance of Yorkshire crossbreds sired by Berkshire (BY), Large Black (LBY), and Tamworth (TY) breeds raised in outdoor hoop structures located in North Carolina. At birth, BY pigs were the lightest ( $\mathrm{p}<0.05 ; 1.34 \pm 0.03 \mathrm{~kg})$, and TY and Yorkshire purebreds (YY) were the heaviest, $1.49 \pm 0.05 \mathrm{~kg}$ and $1.42 \pm 0.03$ $\mathrm{kg}$, respectively, but similar to each other. Yorkshire crossbreds sired by Large Black breeds were intermediate at birth, $1.40 \pm 0.04$ $\mathrm{kg}$; however, by 90 days of age (DOA), they were significantly heavier than all three breeds and continued to be heavier until the end of the experiment at $240 \mathrm{DOA}(\mathrm{p}<0.05)$. The authors concluded that no sire breed provided a real benefit over another for growth performance, and emphasized the high-demand for niche market humanely raised pork with extraordinary quality could potentially provide small-scale pig producers with profit using the outdoor production system.

\section{MEAT QUALITY AND CONSUMER PERCEPTION}

In order to compete with the large production size of the indoor confinement system, relatively smaller outdoor production must find its profit elsewhere through efficiency [7]. Enhanced meat quality is one of the ways in which outdoor reared pig products can earn added value. Efforts to compare the meat quality of indoor and outdoor reared pig products have been made. However, when barrows reared in hoop structure were compared to barrows reared in confinement, the difference in pork quality was limited to their marbling and color scores [16]. When gilts reared in hoop structure were compared to gilts reared in confinement, however, their result differed from that of the barrows; the only difference in meat quality was found in their marbling scores [17]. Outdoor reared gilts had lower marbling score, just like the barrows, but there was no difference in color score.

For the barrows, outdoor pigs, both outdoor farrowed and born, had higher color score for the Minolta $\mathrm{a}^{*}$, which means their appearance was more red than that of indoor farrowed or indoor reared pigs [16]. This gives them a more appealing display, making them more preferable to the consumers. These results were in correspondence with a similar study published by the 
same authors in 2002 [23]. When the birth and rearing environments were compared for the color score, pigs farrowed and reared outdoors had the highest $\mathrm{a}^{*}$ value, followed by pigs farrowed outdoors and reared indoors. Pigs farrowed and reared indoors had the lowest $\mathrm{a}^{*}$ value, giving them the least reddish color $(\mathrm{p}<0.05)$. In the same study, sensory and shear force analyses were performed to test loin palatability. Results showed that birth environment had a significant effect on the pork flavor intensity $(\mathrm{p}<0.01)$. Loins from pigs farrowed outdoors had a higher value than pigs farrowed indoors. When the flavor intensity of pork loin chops was categorized by pig birth and rearing environments, chops from pigs farrowed and reared outdoors had higher scores than chops from the pigs farrowed indoors $(p<0.05)$. Statistically, there was no difference between the outdoor farrowed and reared group and the outdoor farrowed and indoor reared group; however, the outdoor farrowed and reared group had a higher numeric value. Results also showed that pigs reared outdoors had more tender pork $(\mathrm{p}<0.05)$. However, there was no difference in sensory panel tenderness scores.

Some breeds of pigs are known to have better meat quality than others. For example, Berkshire breed is known to have great flavor and is a preferred product among consumers in East Asia. In Japan, high pricing has been established for pork produced from purebred Berkshires because of its superior meat quality [24]. If superior meat quality is maintained in the outdoor environment, these products can receive premium for the added value in niche pork markets which claim product differentiation through superior or unique product quality, and social or credence attributes [25]. Whitley et al [26] compared the pork quality and sensory characteristics of different crossbreds of pigs reared in hoop structures. Yorkshire purebreds (YY) were compared to Yorkshire crossbreds sired by Berkshire (BY), Large Black (LBY), and Tamworth (TY) boars. Meat quality characteristics, such as $\mathrm{pH}$, subjective and objective color scores, marbling score and backfat thickness measures were compared. Sensory panel test was performed which compared the overall, flavor, juiciness and tenderness likings of the meat from different breeds. Breed effect was found on the following fixed effects: subjective color score and $\mathrm{a}^{*}$ color score $(\mathrm{p}<0.05)$. The subjective color score as well as the $\mathrm{a}^{*}$ value were found to be lower for TY and YY. Breed effect was also found in the differences in loin muscle area and backfat thickness $(p<0.01)$. Backfat measures taken at the 1st, 10th, and last rib were higher for LBY than all other breed types. Sensory panel test showed that there was no difference in the overall liking of the different types of breed when all four breeds were tested. However, when only BY, LBY, and YY were compared, YY had the highest overall liking, as well as juiciness liking. Even though the Berkshire breed is a preferred breed in East Asia, BY scored the lowest in the preference ranking $(p<0.05)$. This may be the result of cultural differences in the preferences for pork quality and flavor. In East Asia, fatty pork belly is a preferred product for fresh meat, whereas in the US, the same part is processed to make bacon. The Berkshire breed had the most marbling in its fresh loin chops when compared to other breeds [27]. Less marbling in the pork loin is preferred by consumers in the United States.

Concerns regarding intensive meat production systems expressed by European consumers are similar to those expressed by American consumers. In both the US and Europe, consumers are concerned about food safety, animal welfare and environmental sustainability; however, the long-term financial benefits of outdoor production systems is questionable, and especially in Europe, researchers are asking whether products from such farming systems will ever occupy more than the niche markets [28]. In order to improve the competitiveness of the outdoor products against the indoor products optimized for high production and uniform product quality, while meeting the needs of the consumers looking for animal welfare and environmental sustainability, the quality of the outdoor products should be evaluated in comparison to the indoor products.

In Belgium, when Seghers hybrids were used, the only effect of the rearing environments on the meat quality was the color score [20]. When the CIELAB color coordinates were evaluated, loin area of the outdoor pigs had higher $\mathrm{a}^{*}$ (redness) value. Different results were found in Italy, when Polish-Landrace crossbreds were used, the only difference in carcass quality between the two rearing environments was in backfat thickness [29]. Outdoor reared pigs had a significantly lower backfat thickness; however, the mean values for $\mathrm{pH}$, WHC, drip loss, and shear force of Longissimus lumborum muscle did not differ between the two treatments. When (Swedish Landrace $\times$ Swedish Yorkshire) $\times$ Hampshire pigs were used in Sweden to evaluate the effect of rearing systems on meat quality, the results were different from both the Italian and the Belgian studies. Olsson et al [21] reported that outdoor reared pigs had a lower $\mathrm{pH}$ value, but their color score was not significantly different from that of the confinement pigs. For the water-holding capacity, measured as filter paper wetness, and drip loss, outdoor pigs had lower values; however, the value for cooking loss was higher.

Comparing pork quality across countries in Europe is difficult due to the differing environments. The three studies observed in the present paper were conducted in three different regions of Europe: Benelux, Mediterranean and Nordic. The three regions have different climatic conditions that can cause differences in management practices. The breed of pigs used is one of the management practices that can differ, as certain breeds of pigs are more adapted to certain environments. The effect of breed on meat quality is significant. The results of the 2005 study of the Seghers hybrids in Belgium by Millet et al [20] were different from the results of the 2004 study of the Pietrain $\times$ (Belgian Landracex Duroc) crossbreds in Belgium, also by Millet et al [30]. In the 2004 study [30], when Pietrain $\times($ Belgian Landrace $\times$ Duroc) crossbreds were used, rearing environments had a significant impact not only on the color score, but also on the $\mathrm{pH}$ values of the loin and 
the intramuscular fat content. Outdoor reared pigs had lower $\mathrm{pH}$ values at 40 -minute $(\mathrm{p}<0.01)$ and 24 -hour $(\mathrm{p}<0.05)$ postmortem, as well as a lower intramuscular fat content $(\mathrm{p}<0.05)$. Also, when the CIELAB color coordinates were evaluated, loin area of the outdoor pigs had higher $\mathrm{a}^{*}$ (redness) and $\mathrm{b}^{*}$ (yellowness) values.

Similar to the meat quality results, consumer perception and preference of meat was different across Europe. Several studies investigated consumer liking and perception of pork in different countries. Bryhni et al [31] looked specifically at consumers in Denmark, Norway and Sweden, with a focus on determining the sensory characteristics associated with consumer definition of pork quality and what were the most important characteristics and the main reasons for buying pork to explain the possible differences between consumers in these countries. Of the consumers in the three countries, Norwegian consumers were the most negative towards pork quality, followed by Danish and Swedish consumers, respectively. While the Norwegian consumers had the most negative comments to make related to pork, such as being dry, more off-flavor, flavor likely to change during freezing, and easily gets rancid, the Danish consumers perceived pork as tasteless, with more warmed-over flavor, fatty and often smelling badly when fried. According to the researchers, these results are associated with the eating behavior of the consumers in the different countries. In Sweden, pork is consumed mostly as freshly fried pork, which can be compared to the more ready-to-eat products in Denmark. Furthermore, Sweden had the highest frequency of pork consumption among the groups, which may have also contributed to the differences in perceptions.

A similar study was reported in 2003 that looked at the decision-making factors in fresh pork purchasing and consumer attitudes towards today's pig production systems in France, England, Sweden and Denmark [32]. When asked to name some of the factors that make a good pork quality, consumers from all four countries named fat cover, price, country of origin and place of purchase as important indicators of good pork quality. Interestingly, even though country of origin was one of four most important factors determining pork quality, it was also one of the most distrusted. Consumers expressed some confusion when country of origin was provided as a label, asking what it actually meant. They were unsure whether it meant the place the animals were raised, slaughtered, or processed. Similar confusion was expressed over organic products. When asked about the pig production systems today, consumers from all four countries agreed that the majority of the systems are intensive and had a negative view on the intensive systems, describing them as inhumane. However, all four groups also admitted that their image of the pig production system was largely influenced by the media, and raised doubts regarding their reality. When asked about the effect of production method on meat quality, all four groups stated that there is a direct effect. However, how the production method affected the meat quality differed amongst groups. For example, while the English and French groups believed that outdoor pro- duction results in better quality meat, Swedish women and Danish groups stated that the flavor of the outdoor pork products did not differ from that of the indoor pork products. Also, even within the same country, differing opinions were observed. While some participants from England related off or bad flavors with intensive indoor system, others related the same characteristics with free range rearing. These results were somewhat different from a study conducted by Dransfield et al [28]. When information regarding the production system and country of origin were given, consumers from the same four countries offered about $5 \%$ more for outdoor reared products and home-raised products.

\section{HEALTH}

Outdoor production system promotes animal welfare by allowing the animals outside access, and naturally, the animals come in contact with the soil and become vulnerable to the large number of harmful bacteria, viruses and parasites that can cause economic losses. Contrastingly, outdoor reared pigs are less susceptible to airborne contaminants compared to the indoor reared pigs. In an indoor production system, the animals are confined inside a building at a higher density, which can increase the chance of the aerosol transmission of the infectious diseases. The amount of research on the aerosol transmission of diseases in outdoor production systems is limited. However, the indoor production systems have been extensively studied by many researchers [33]. According to Stark [33], excretion by infected animals, critical concentration, and contact between susceptible animals and causative agent are required for the transmission of respiratory disease agents, and the impact of the disease transmission depends on a number of environmental factors, such as herd size, stocking density and shared airspace. In an indoor rearing environment, where the herd size and the stocking density are larger and the shared airspace is smaller than outdoor rearing environments, the animals have easier access to excretion by infected animals and contact between susceptible animals and causative agents is easily made due to the enclosed nature of the confinement buildings.

A survey of different housing systems in Danish pig farms showed that outdoor rearing environment provided particularly favorable conditions for helminth transmission [34]. All of the 15 helminths of major economic importance listed by Nansen and Roepstorff [34] were found in the outdoor reared pigs, while only 3 of the listed helminths were found in pigs intensively reared indoors. The extent to which the animals are exposed to the helminths may vary according to the production system. Ascaris suum is one of the helminths listed by them that is associated with a major economic loss if a herd is affected. When Jolie et al [35] studied the effects of production systems on the presence and severity of liver white spots in feeder pigs, which is indicative of ascarid larval migration, they found that the outdoor reared pigs had a significantly higher liver score $(\mathrm{p}<0.001)$, which meant 
that the ascarid larval fibroma, or the liver white spots, were significantly more present and more severe in the outdoor reared pigs. The authors concluded that the low helminth presence in the indoor herd was due to the improved hygiene and physical conditions through the use of slatted floors that allowed the feces to deposit through, away from the pigs.

One of the main goals of outdoor production systems is to provide welfare for the animals. The presence of straw-beddings or pastures allows the animals to roam free, graze and root as they desire. Though not significantly different, when Yonezawa et al [36] compared the behaviors of indoor and outdoor reared pigs, the outdoor reared pigs showed a larger number of rooting episodes $(\mathrm{p}=0.05)$ and a longer total time of rooting behaviors ( $\mathrm{p}$ $=0.06$ ). Outdoor pigs were also found to have fewer injuries to the body [37]. When pigs in outdoor paddocks, straw yards or fully slatted pens were compared, pigs reared in outdoor paddocks or straw yards had significantly fewer numbers of injuries $(\mathrm{p}<$ $0.05)$ and a smaller adventitious bursitis score $(\mathrm{p}<0.01)$. In a similar study, Tozawa et al [38] compared the behaviors and the wounds on the body of pigs reared in five different environments: an indoor housing system, an outdoor pasturing system, a concrete floor paddock system, a concrete floor paddock system with fresh grass, or a soil floor paddock system. They concluded that the presence of a soil floor is the most important aspect of a pig production system that best improves animal welfare.

Despite the improved welfare of animals reared in outdoor production systems, one problem seems to persist. According to the Swedish Animal Health Service, joint health has become a major issue, as indicated by the increased number of joints rejected at slaughter. Joint lesion is a leading cause of lameness [39], and lameness reduces the level of welfare for the animals. Osteochondrosis is a general term used to describe leg problems in pigs and is the main cause of leg weakness. When van Grevenhof et al [40] compared the joint health of pigs reared in different housing systems, a partially slatted concrete floor or a deep litter floor with extra space allowance, they found that the conventionally reared pigs were more affected by Osteochondrosis than the pigs reared in the deep litter floor. Similar results were found by Etterlin et al [41]. The authors concluded that the extra space allowed for the deep litter herd strengthened the joint supportive tissue and provided some pain relief through exercise.

\section{US PORK NICHE MARKET}

The rapid industrialization of pork production caused a negative reaction from some of the public. Such opposition comes from many different aspects, such as sociological, ethical, environmental and sanitary concerns [42]. The indoor system created an anticorporate sentiment in some of the consumers who worry that the large production size of the indoor system will overtake the market and negatively impact the rural communities. Furthermore, some of the public have concerns about the welfare of the animals as well as the sustainability of the environment. The US pork niche market specifically targets these consumers. They claim product differentiation through social or credence attributes and add value to their product through superior or unique quality to better compete with the large production size of the indoor confinement systems [25]. Though difficult to measure in the pork, the pork niche market uses social or credence attributes of the outdoor production system to promote sales in their product. According to Honeyman et al [25], some of the claims they make include freedom from antibiotic and growth promoters; local family farm production; natural, organic, outdoor, or bedded rearing conditions; humane rearing; known origin; environmentfriendliness; and no animal by-products in the feed.

\section{CONCLUSION}

The world is becoming greener. People show more concern about where their food comes from and how it is produced, and the food industry is moving towards the same direction to meet the needs of their newly enlightened consumers. Large restaurant chains, such as McDonald's, are making changes in their policy to support environmental sustainability and animal welfare. In 2012, McDonald's announced its 10-year plan to end the use of gestation stalls for pregnant sows [43]. These changes that are occurring in the food industry can help strengthen the pork niche markets and broaden the target audience for small farmers practicing outdoor swine production. In order to maximize the effect, however, farmers and researchers must find a way to improve the product quality and scientifically support the product differentiation.

\section{CONFLICT OF INTEREST}

We certify that there is no conflict of interest with any financial organization regarding the material discussed in the manuscript.

\section{REFERENCES}

1. 2012 Census of Agriculture: United States summary and state data [Internet]. USDA; 2014 [cited 2017 Feb 10]. Available from: https:// www.agcensus.usda.gov/Publications/2012/Full_Report/Volume_1, Chapter_1_US/usv1.pdf

2. Pork stats. 2014. Pork checkoff. National Pork Board, Des Moines, IA, USA.

3. Kapel CMO. Changes in the EU legislation on Trichinella inspection - New challenges in the epidemiology. Vet Parasitol 2005;132:189-94.

4. von Borell E, Sorensen JT. Organic livestock production in Europe: aims, rules and trends with special emphasis on animal health and welfare. Livest Prod Sci 2004;90:3-9.

5. Früh B, Bochicchio D, Edwards S, et al. Description of organic pig production in Europe. Org Agric 2014;4:83-92.

6. Hinrichs CC, Welsh R. The effects of the industrialization of US lives- 
tock agriculture on promoting sustainable production practices. Agric Hum Values 2002;20:125-41.

7. Dawkins MS. Animal welfare and efficient farming: is conflict inevitable? Anim Prod Sci 2017;57:201-8.

8. Miao ZH, Glatz PC, Ru YJ. Review of production, husbandry and sustainability of free-range pig production systems. Asian-Australas J Anim Sci 2004;17:1615-34.

9. Honeyman MS. Extensive bedded indoor and outdoor pig production systems in USA: current trends and effects on animal care and product quality. Livest Prod Sci 2005;94:15-24.

10. Johnson AK, Morrow-Tesch JL, McGlone JJ. Behavior and performance of lactating sows and piglets reared indoors or outdoors. J Anim Sci 2001;79:2571-9.

11. Vaillancourt JP, Stein TE, Marsh WE, Leman AD, Dial GD. Validation of producer-recorded causes of preweaning mortality in swine. Prev Vet Med 1990;10:119-30.

12. Johnson, AK, McGlone, JJ. Fender design and insulation of farrowing huts: effects on performance of outdoor sows and piglets. J Anim Sci 2003;81:955-64.

13. Choi W, Nassif N, Whitley N, Oh SH. Comparison of temperature and humidity in three types of outdoor farrowing huts. Appl Eng Agric 2014;30:241-7.

14. Akos K, Bilkei G. Comparison of the reproductive performance of sows kept outdoors in Croatia with that of sows kept indoors. Livest Prod Sci 2004;85:293-8.

15. Lindgren Y, Lundeheim N, Boqvist S, Magnusson U. Reproductive performance in pigs reared under organic conditions compared with conventionally reared pigs. Acta Vet Scand 2013;55:33.

16. Gentry JG, McGlone JJ, Miller MF, Blanton JR. Environmental effects on pig performance, meat quality, and muscle characteristics. J Anim Sci 2004;82:209-17.

17. Patton BS, Huff-Lonergan E, Honeyman MS, et al. Effects of deepbedded finishing system on market pig performance, composition and pork quality. Animal 2008;2:459-70.

18. Honeyman MS, Harmon JD. Performance of finishing pigs in hoop structures and confinement during winter and summer. J Anim Sci 2003;81:1663-70.

19. Dourmad JY, Hassouna M, Robin P, et al. Influence of pig rearing system on animal performance and manure composition. Animal 2009;3:606-16.

20. Millet S, Raes K, Van den Broeck W, De Smet S, Janssens GPJ. Performance and meat quality of organically versus conventionally fed and housed pigs from weaning till slaughtering. Meat Sci 2005;69:335-41.

21. Olsson V, Andersson K, Hansson I, Lundstrom K. Differences in meat quality between organically and conventionally produced pigs. Meat Sci 2003;64:287-97.

22. Whitley N, Morrow W, See MT, Oh S-H. Comparison of growth performance of antibiotic-free yorkshire crossbreds sired by berkshire, large black, and tamworth breeds raised in hoop structures. AsianAustralas J Anim Sci 2012;25:1351-6.

23. Gentry JG, McGlone JJ, Miller MF, Blanton JR. Diverse birth and rearing environment effects on pig growth and meat quality. J Anim
Sci 2002;80:1707-15.

24. Suzuki K, Shibata T, Kadowaki H, Abe H, Toyoshima T. Meat quality comparison of Berkshire, Duroc, and crossbred pigs sired by Berkshire and Duroc. Meat Sci 2003;64:35-42.

25. Honeyman MS, Pirog RS, Huber GH, Lammers PJ, Hermann JR. The United States pork niche market phenomenon. J Anim Sci 2006;84: 2269-75.

26. Whitley N, Hanson D, Morrow W, See MT, Oh SH. Comparison of pork quality and sensory characteristics for antibiotic free Yorkshire crossbreds raised in hoop houses. Asian-Australas J Anim Sci 2012;25: 1634-40.

27. Brewer MS, Jensen J, Sosnicki AA, et al. The effect of pig genetics on palatability, color and physical characteristics of fresh pork loin chops. Meat Sci 2002;61:249-56.

28. Dransfield E, Ngapo TM, Nielsen NA, et al. Consumer choice and suggested price for pork as influenced by its appearance, taste and information concerning country of origin and organic pig production. Meat Sci 2005;69:61-70.

29. Maiorano G, Kapelanski W, Bocian M, Pizzuto R, Kapelanska J. Influence of rearing system, diet and gender on performance, carcass traits and meat quality of Polish Landrace pigs. Animal 2013;7:341-7.

30. Millet S, Hesta M, Seynaeve M, et al. Performance, meat and carcass traits of fattening pigs with organic versus conventional housing and nutrition. Livest Prod Sci 2004;87:109-19.

31. Bryhni EA, Byrne DV, Rødbotten M, et al. Consumer perceptions of pork in Denmark, Norway, and Sweden. Food Qual Pref 2002;13: 257-66.

32. Ngapo TM, Dransfield E, Martin J-F, et al. Consumer perceptions: pork and pig production. Insights from France, England, Sweden and Denmark. Meat Sci 2003;66:125-34.

33. Stark KDC. Epidemiological investigation of the influence of environmental risk factors on respiratory diseases in swine - a literature review. Vet J 2000;159:37-56.

34. Nansen P, Roepstorff A. Parasitic helminths of the pig: factors influencing transmission and infection levels. Int J Parasitol 1999;29:877-91.

35. Jolie R, Bäckström L, Pinckney R, Olson L. Ascarid infection and respiratory health in feeder pigs raised on pasture or in confinement. Swine Health Prod 1998;6:115-20.

36. Yonezawa T, Takahashi A, Imai S, et al. Effects of outdoor housing of piglets on behavior, stress reaction and meat characteristics. AsianAustralas J Anim Sci 2012;25:886-94.

37. Guy JH, Rowlinson P, Chadwick JP, Ellis M. Health conditions of two genotypes of growing-finishing pig in three different housing systems: implications for welfare. Livest Prod Sci 2002;75:233-43.

38. Tozawa A, Tanaka S, Sato S. The effects of components of grazing system on welfare of fattening pigs. Asian-Australas J Anim Sci 2016; 29:428-35.

39. Jensen TB, Toft N. Causes of and predisposing risk factors for leg disorders in growing-finishing pigs. CAB Rev Perspect Agric Vet Sci Nutr Nat Res 2009;4:No. 010.

40. van Grevenhof EM, Ott S, Hazeleger W, et al. The effects of housing system and feeding level on the joint-specific prevalence of osteochon- 
drosis in fattening pigs. Livest Sci 2011;135:53-61.

41. Etterlin PE, Morrison DA, Österberg J, et al. Osteochondrosis, but not lameness, is more frequent among free-range pigs than confined herd-mates. Acta Vet Scand 2015;57:63.

42. Davies PR. Intensive swine production and pork safety. Foodborne Pathog Dis 2001;8:189-201.
43. McComb L, Rump J. McDonald's USA Outlines 10-Year Plan for Ending Gestation Stall Use [Internet]. McDonald's Newsroom; 2012 [cited 2017 Feb 15]. Available from: http://news.mcdonalds.com/ press-releases/mcdonald-s-usa-outlines-10-year-plan-for-endingge-nyse-mcd-0893947 